\title{
Research on Coal Tar Pitch Catalytic Oxidation and Its Effect on the Emission of PAHs during Co-Carbonation with Coal
}

\author{
Liqing Chen ${ }^{1}{ }^{(}$, Fanhui Guo ${ }^{1}\left(\mathbb{D}\right.$, Jianjun $\mathrm{Wu}^{1, *}$, Ping $^{2} \mathbf{L i}^{2}$ and Yixin Zhang ${ }^{3,4, *}$ \\ 1 School of Chemical Engineering and Technology, China University of Mining and Technology, \\ Xuzhou 221116, China; TS19040037A31@cumt.edu.cn (L.C.); cumtgfh@163.com (F.G.) \\ 2 State Key Laboratory of High-Efficiency Utilization of Coal and Green Chemical Engineering, \\ Ningxia University, Yinchuan 750021, China; liping@nxu.edu.cn \\ 3 National Engineering Research Center of Coal Preparation and Purification, China University of Mining and \\ Technology, No. 1 Daxue Road, Xuzhou 221116, China \\ 4 Shandong Xuanyuan Scientific Engineering and Industrial Technology Research Institute Co., Ltd., Longgu, \\ Juye, Heze 274918, China \\ * Correspondence: wujj@cumt.edu.cn (J.W.); yixinzhang@cumt.edu.cn (Y.Z.)
}

check for updates

Citation: Chen, L.; Guo, F.; Wu, J.; Li, P.; Zhang, Y. Research on Coal Tar Pitch Catalytic Oxidation and Its Effect on the Emission of PAHs during Co-Carbonation with Coal. Catalysts 2021, 11, 1428. https:// doi.org/10.3390/catal11121428

Academic Editor: Morris D. Argyle

Received: 16 October 2021

Accepted: 22 November 2021

Published: 24 November 2021

Publisher's Note: MDPI stays neutral with regard to jurisdictional claims in published maps and institutional affiliations.

Copyright: (c) 2021 by the authors. Licensee MDPI, Basel, Switzerland. This article is an open access article distributed under the terms and conditions of the Creative Commons Attribution (CC BY) license (https:/ / creativecommons.org/licenses/by/ $4.0 /)$.

\begin{abstract}
Coal tar pitch (CTP) is abundant and widely used, but its properties will be affected due to oxidation aging during storage. In this study, CTP was oxidized by simulating the air oxidation process, and the change of chemical structure has been analyzed by Fourier transform infrared spectroscopy (FTIR), X-ray diffraction (XRD), and both gas chromatography and mass spectrometry (GCMS). The effects of the oxidized and unoxidized CTP co-carbonization with coal on the polycyclic aromatic hydrocarbons (PAHs) emission were detected by GCMS. The small and medium-molecule aromatic substances were reduced during CTP oxidation, while the intermolecular condensation reaction increased the macromolecules content. The catalytic can effectively facilitate the dehydrogenation and condensation reaction of CTP and the entry of oxygen molecules, which leads to the increase of oxygen-containing groups and the decrease of PAHs. Compared to the raw CTP, the catalytic oxidized CTP significantly reduced the emissions of toxic PAHs during the co-carbonization with coal. A possible catalytic mechanism of CTP catalytic oxidation is proposed.
\end{abstract}

Keywords: coal tar pitch; catalyst air oxidation; $\mathrm{AlCl}_{3}$; co-carbonization; PAHs

\section{Introduction}

Coal tar pitch (CTP) is a by-product of coal coking. Thus, it has a good affinity with coal and can effectively improve the coke quality as a binder. However, it is easy to be aged during storage, thereby losing volatile substances and producing asphaltenes [1] Due to the association of polar components in asphalt binder, it becomes harder and more brittle during oxidative aging under the premise of adequate supply of reactive oxygen [2]. Thermal oxidative aging is the main aging factor, and there are two views concerning this phenomenon. One view is that the aging mechanism of thermal-oxidative is oxidation (that is, asphalt absorbs oxygen and reacts to produce asphaltenes, salts, and acids). Another view is that asphalt molecules dehydrogenate at high temperatures to generate unsaturated carbon chains, which absorb enough energy to be broken, followed by an oxygen absorption reaction to generate carbonyl. However, at low temperatures $\left(60^{\circ} \mathrm{C}\right)$, the available heat energy is little to make the carbon chain dehydrogenation reaction, implying that no carbonyl is formed.

The process of thermal-oxidative aging responds to the volatilization of the lighter components and the gelled mixture oxidation [3]. Microscopically, the aging of the asphalt is attributed to the chemical structure changes [4], such as oxidation, leads to the formation of dealkylated and oxygenated structures. Meanwhile, the aromatic structures, condensation, and free radicals decomposition occur simultaneously [5]. Earlier, M.A. Quddus [6] used the de-adsorption chromatography to evaluate the chemical changes of asphalt 
during air blowing. D. R. Liang studied the structural changes during thermal-oxidative aging of CTP by using Fourier transform infrared spectroscopy (FTIR), and divided the thermal-oxidative aging process into two stages. Daniel J. Oldham [7] proposed a critical aging point (CAP) for asphalt and concluded that the asphalt aging quickly in the early stages, mainly due to oxidation, and the reaction changes to aromatization and carbonization as the aging time increases. Asphalt binder components with high polarization rates (e.g., asphaltenes and resins polarization rates between 527-876) are more susceptible to oxidation than low polarization rates (e.g., saturates polarization rates less than 380) [8]. When the asphalt reacts with oxygen, its molecular polarity changes, causing a decrease in aromatics, saturates, and resins, and an increase in asphaltenes, ultimately reducing the thermal sensitivity and ductility. Elemental composition and structural parameters based on ultraviolet (UV) and nuclear magnetic resonance (NMR) showed that straight-chain hydrocarbons are converted to cycloalkanes in air, which dehydrogenated to produce aromatics and increased the molecular mass of asphalt. To obtain CTP with high condensation and storage stability, chemical oxidation, and other methods (e.g., thermal polymerization and pressurized thermopolymerization) were utilized to modify the pitch.

Ayoe Benk [9] stated that the improvement in the quality of asphalt as a binder is due to the increase in asphaltene by the action of oxygen in the air, therefore, high-strength coal with a tensile strength of $50.45 \mathrm{NM} / \mathrm{m}^{2}$ was obtained using air-oxidized CTP blended with phenolic resin as a coal binder and cured at $200{ }^{\circ} \mathrm{C}$ for $5 \mathrm{~h}$. In addition, the air oxidized CTP can also be used as a raw material for preparing materials such as mesophase carbon microspheres and carbon fibers $[10,11]$. Above, CTP can be used effectively after air oxidation. Commonly methods to examine the chemical composition and structure of asphalt include FTIR, Gel chromatography (GPC), atomic force microscopy (AFM), etc. [12-15]. Among these, FTIR is the most commonly used [3,5]. Yihua Nie et al. [16] analyzed the asphalt aging behavior by FTIR spectroscopy and concluded that the changes in asphalt FTIR index and physical parameters with aging time were consistent with the aging kinetics. X-ray diffraction (XRD), as a means of rapid material analysis, can analyze the molecular structure and chemical composition effectively. It is possible to know whether the samples are amorphous or crystalline according to XRD spectra [17]. The spectra of amorphous samples show large peak packet patterns without delicate spectral structures [18], such as amorphous samples of coal and asphalt [19]. In contrast, crystalline structures display the characteristic peak spectral lines of substances, such as graphene [15]. As organic pollutants, polycyclic aromatic hydrocarbons (PAHs) are teratogenic, carcinogenic, mutagenic, and contain other hazards. The emission of PAHs can seriously pollute the environment and cause irreversible damage to the body, even DNA damage in severe cases [20,21]. The detection methods of PAHs are relatively mature, and the commonly used are gas chromatography (GC) [22], gas chromatography and mass spectrometry (GCMS) [23-25], high performance liquid chromatography (HPLC) [26], UV spectrophotometry [27], etc.

CTP is derived from coal and has a similar chemical structure to coal. The gas produced by CTP interacts with the coal in the carbonization process, transforming the coal in-situ, thus the bonding of the coal are enhanced [28]. Therefore, adding suitable CTP to coking can effectively improve the coke quality [29-31]. Coking is considered to be a major source of PAHs, which pollute the atmosphere, soil, and water [32,33]. It was found that the most PAHs were generated in the pre-coking period, tetracyclic aromatics accounted for the major part among these PAHs $[34,35]$. Benzo(a)pyrene $(\mathrm{BaP})$ is the main pollutant of PAHs pollution with highly carcinogenic effects, and its concentration is higher than the emission standard value [36].

It was reported that $\mathrm{AlCl}_{3}$ has a foster effect on the oxidation process of CTP [37]. When $\mathrm{AlCl}_{3}$ is used as a catalyst, $\mathrm{HCl}$, olefins and aromatics can undergo alkylation reactions, which proceed as in Scheme 1 [38]. 


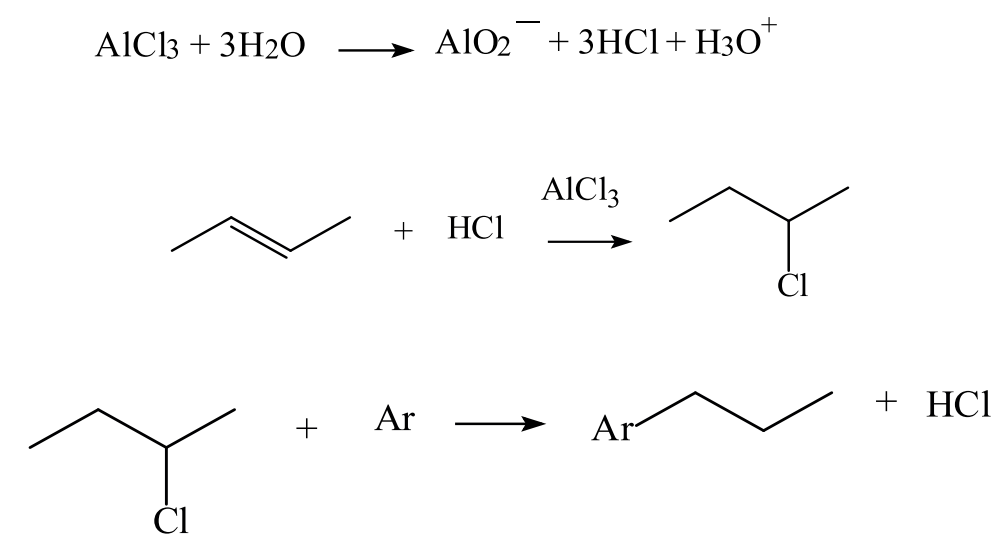

Scheme 1. $\mathrm{AlCl}_{3}$-catalyzed alkylation reaction [38].

Studies related to $\mathrm{AlCl}_{3}$ as a catalyst point out that $\mathrm{AlCl}_{3}$ can effectively stimulate some organic synthesis reactions. For example, the Diels-Alder reaction (Scheme 2) [39,40].<smiles>C=CC(=C)C</smiles><smiles>C=CC(=C)C</smiles><smiles>C=CC(=C)C</smiles><smiles>C=CC(=O)OC</smiles><smiles>COC(=O)C1CC=C(C)CC1</smiles>

Scheme 2. Diels-Alder reaction $[39,40]$.

In this study, the effect of oxidation on CTP structure was analyzed by different degrees of air oxidation using FTIR, XRD, and GCMS to provide theoretical direction for the effective utilization of CTP after air aging. The air oxidation process of CTP was catalyzed by $\mathrm{AlCl}_{3}$, and the catalytic mechanism of $\mathrm{AlCl}_{3}$ in the process was discussed. Analysis of the air oxidized CTP effect on the 16 PAHs emission during the co-carbonization was characterized by GCMS.

\section{Results and Discussion}

\subsection{Physical Properties Analysis of CTP and Raw Coal}

As shown in Table 1, the volatile (V) content of CTP decreased gradually with air oxidation, which may be caused by dehydrogenation condensation of oligomers and escape of light components in CTP [41]. Research has shown that air oxidation is more beneficial for improving the coking value (CV) of CTP than other oxidation methods [42]. In Table 1, the CV of CTP increased significantly after oxidation, which can provide insights into the preparation of high-quality impregnated bitumen [43]. 
Table 1. The characteristic properties of air oxidized CTP.

\begin{tabular}{cccccc}
\hline Sample & CTP & CTP-1 & CTP-3 & CTP-6 & CTP-10 \\
\hline $\mathrm{V}_{\text {ad }}(\%)$ & 84.41 & 82.88 & 77.09 & 77.07 & 71.86 \\
CV (\%) & 25.96 & 30.57 & 33.32 & 34.05 & 38.08 \\
\hline
\end{tabular}

Notes: "ad", air dry base.

\subsection{Analysis of the Effect of Catalytic Oxidation on Coal Tar Pitch}

\subsubsection{Analysis on Properties of Catalytic Oxidized Coal Tar Pitch}

The catalyst promotes the air oxidation of CTP. Data in Tables 1 and 2 have shown that the volatile content of CTP decreased after air oxidation. Figure 1 was drawn for visualizing the changes of the $\mathrm{V}$ value in the samples with catalyst and non-catalyst. The $\mathrm{V}$ value of the CTP with catalyst decreased from $84.41 \%$ to $70.99 \%$ within $6 \mathrm{~h}$, and the little change was observed with the extension of time. However, the sample with non-catalyst only decreased to $77.07 \%$, then continued to decrease over time. The $\mathrm{V}$ value decreased significantly with the addition of catalyst, indicating that the catalyst can boost the escape of light components.

Table 2. The characteristic properties of catalytic air oxidized CTP.

\begin{tabular}{cccccc}
\hline Sample & CTP & CTP-A1 & CTP-A3 & CTP-A6 & CTP-A10 \\
\hline $\mathrm{V}_{\mathrm{ad}}(\%)$ & 84.41 & 80.89 & 76.74 & 70.99 & 70.05 \\
CV $(\%)$ & 25.96 & 29.59 & 28.64 & 39.65 & 34.73 \\
\hline
\end{tabular}

Notes: "ad", air dry base.

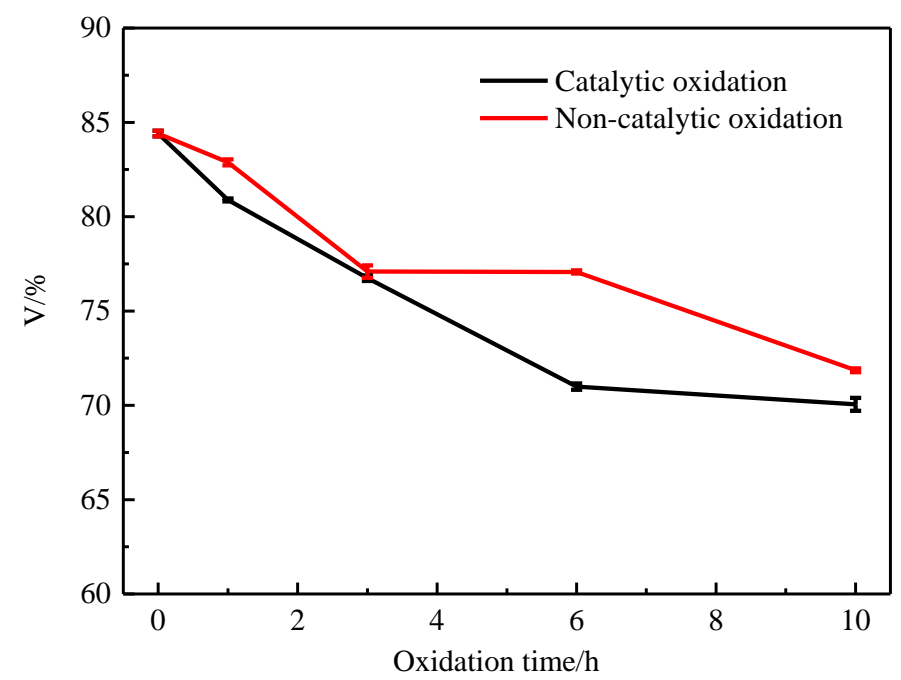

Figure 1. Changes of V content in CTP for catalytic oxidation and non-catalytic oxidation.

The air oxidation of CTP shows two stages. Analyzing the changes of CTP during oxidation, it is considered that the first stage of oxidation mainly relies on air blowing to make the light components and small molecules in CTP be carried away. The second stage is dominated by the condensation reaction of aromatic molecules to form larger molecular aromatics [3]. As shown in Figures 1 and 2, both the V and toluene insoluble (TI) in the CTP are basically stable after $6 \mathrm{~h}$ of catalytic oxidation, which expresses that most of the light components have escaped. Therefore, the longer reaction time is beneficial to the oxidative condensation of CTP molecules. Moreover, the light component stabilized by air oxidation is reduced, which can reduce the emission of polluting gases during storage [44]. 


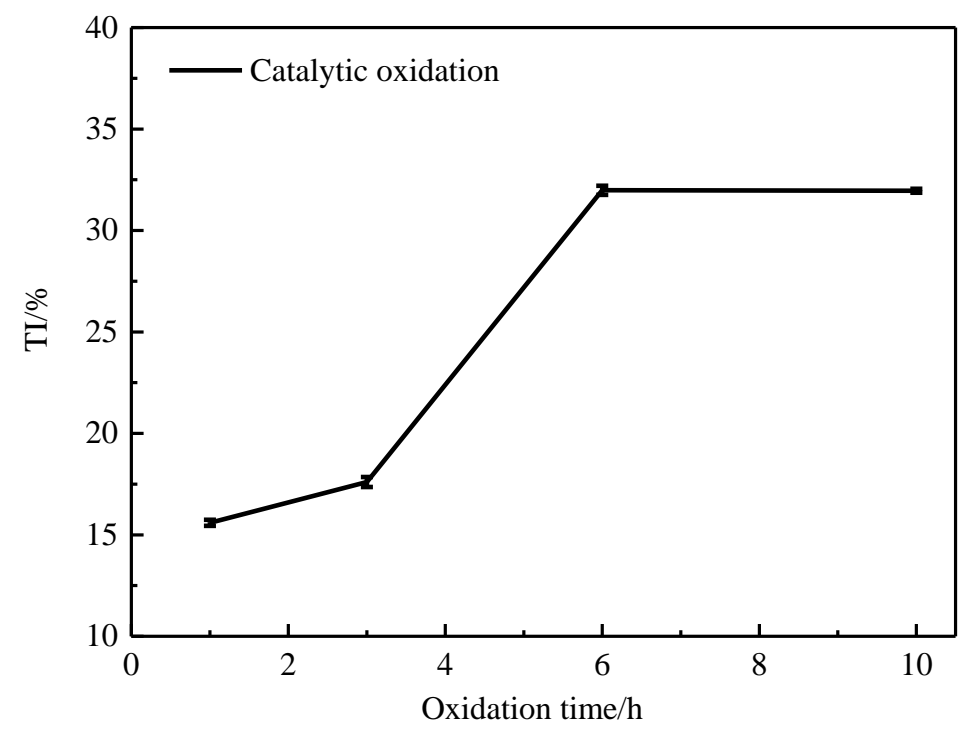

Figure 2. Change of TI content in CTP with catalytic oxidation time.

\subsubsection{Elemental Analysis}

Table 3 has shown that the oxygen content increased significantly after air oxidized $10 \mathrm{~h}$. When CTP is oxidized, the aromatic molecules with alkyl side chains (Ar) in CTP are dealkylated to form aromatic radicals $\left(\mathrm{Ar}^{*}\right)$. Then the oxygen in the air interacts with the aromatic radicals to generate aromatic oxygen radicals $\left(\mathrm{ArO}^{*}\right)$, thus oxygen is introduced [5]. The CTP's oxygen content increased by $54.16 \%$ with catalyst, while it only can be increased by $8.83 \%$ with non-catalyst, it is clear that the catalyst promoted the transfer of oxygen molecules in the asphalt, which facilitated the oxygen molecules to combine with the active molecules.

Table 3. Elemental content of the original CTP, the air oxidized $10 \mathrm{~h} \mathrm{CTP}$, and the catalytic air oxidized $10 \mathrm{~h} \mathrm{CTP.}$

\begin{tabular}{cccccc}
\hline Sample & $\boldsymbol{n}(\mathbf{\%})$ & $\mathbf{C ~ ( \% )}$ & $\mathbf{H ~ ( \% )}$ & $\mathbf{O} \mathbf{( \% )}$ & C/H Ratio \\
\hline CTP & 0.87 & 83.48 & 6.678 & 7.794 & 12.5003 \\
CTP-10 & 0.83 & 83.51 & 6.619 & 8.482 & 12.6166 \\
CTP-A10 & 0.73 & 80.23 & 6.258 & 12.015 & 12.8196 \\
\hline
\end{tabular}

More pronounced dehydrogenation undergoes in CTP with the addition of catalysts, it is more likely related to cyclization and/or aromatization [6]. The atomic $\mathrm{C} / \mathrm{H}$ ratio in CTP increased by oxidation, signaling an increase in heavy components, which means a decrease in aromatic or saturated aliphatic structure [1].

The oxidized CTP has a decreased $n$ content compared to the original, which may be due to the reaction of nitrogen with hydrogen to form ammonia [45]. In addition, the decrease of $\mathrm{S}$ and the increase of $\mathrm{O}$ in CTP after oxidation imply that the polar components increase [46].

\subsubsection{Fourier Transformed Infrared Spectroscopy}

The FTIR spectra of catalytic oxidized and the parent CTP are shown in Figure 3. All samples have a broad absorption at $3400 \mathrm{~cm}^{-1}$ by the stretching vibration of the $\mathrm{O}-\mathrm{H}$, denoting the presence of hydroxyl groups or adsorbed water. The peaks at $2920 \mathrm{~cm}^{-1}$ and $2850 \mathrm{~cm}^{-1}$ belong to the telescopic vibration of aliphatic $\mathrm{C}-\mathrm{H}$ and the antisymmetric telescopic vibration of saturated $\mathrm{C}-\mathrm{H}$ in methyl $\left(-\mathrm{CH}_{3}\right)$, respectively, their enhancement indicates an increase in aliphatic content. The sharp peak at $2920 \mathrm{~cm}^{-1}$ is enhanced after $6 \mathrm{~h}$ of oxidation, proving that the condensation reaction between aromatic molecules. The peak at $1600 \mathrm{~cm}^{-1}$ is caused by the $\mathrm{C}=\mathrm{C}$ stretching vibration of the aromatic ring [14]. The 
absorption at $1440 \mathrm{~cm}^{-1}$ is characteristic of the out-of-plane bending vibration of the C-H bond in the methyl or methylene group and the aromatic ring skeleton vibration, which intensity increases, reflecting the $\mathrm{CH}_{2}$ content of the aromatic ring increases. The extensive absorption at $1180 \mathrm{~cm}^{-1}$ is caused by the $\mathrm{C}-\mathrm{O}-\mathrm{C}$ stretching vibration on the aromatic ring, which increases with the oxidation time, meaning that the condensation reactions between the aromatic rings are mainly proceeded by Ar-R-O-R-Ar bonding [10]. The weak peaks in the range of $700-900 \mathrm{~cm}^{-1}$ represent the absorption in the aromatic substitution region, which is induced by the out-of-plane vibration of the aromatic hydrocarbon structure [47]. Moreover, the extensive characteristic peaks of the $\mathrm{C}=\mathrm{C}$ skeletal bond of the aromatic ring near $1600 \mathrm{~cm}^{-1}$ and the weak absorbance peaks of hydrogen in the aromatic ring near $3040 \mathrm{~cm}^{-1}, 805 \mathrm{~cm}^{-1}$, and $743 \mathrm{~cm}^{-1}$ denote the presence of aromatic structures in CTP [48].

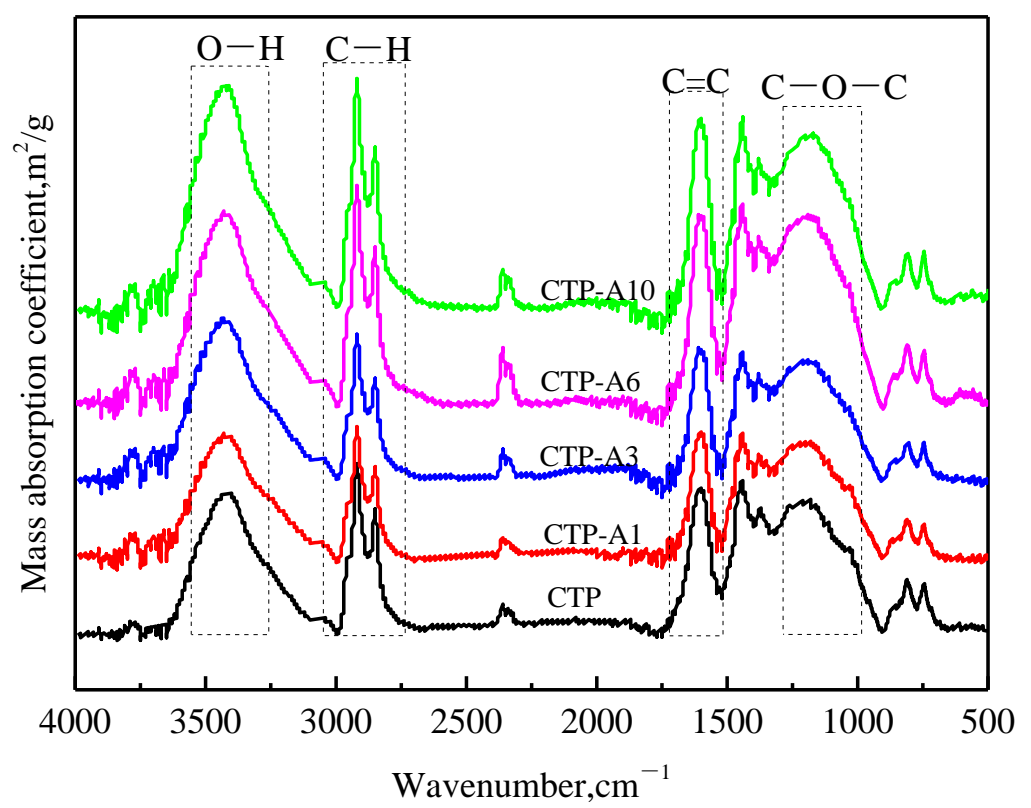

Figure 3. FTIR spectra of original CTP and catalytic oxidation CTP. (CTP, raw CTP; CTP-A1, $\mathrm{AlCl}_{3}$ catalyzed air oxidation for $1 \mathrm{~h} ; \mathrm{CTP}-\mathrm{A} 3, \mathrm{AlCl}_{3}$ catalyzed air oxidation for $3 \mathrm{~h}$; $\mathrm{CTP}-\mathrm{A} 6, \mathrm{AlCl}_{3}$ catalyzed air oxidation for $1 \mathrm{~h}$; CTP-A10, $\mathrm{AlCl}_{3}$ catalyzed air oxidation for $10 \mathrm{~h}$.).

\subsubsection{X-ray Diffraction Analysis}

Figure $4 \mathrm{a}$ shows that the peaks of all samples are hill-like shapes, which strength decreases after air oxidation. The peak strength decreases obviously with the addition of catalyst, demonstrating that the catalyst boosts the asphalt molecules polymerization [49]. According to previous studies, the hill-like peak is formed by the dispersion of $\gamma$ and (002) peaks. The XRD spectra of graphite, coke, and coal generally appear (002) peaks which have been confirmed to be produced by condensed aromatic nuclei. The aromatic lamellae with many aromatic rings, large lamellae structure, and the high degree of unit structure association are beneficial to the orderly accumulation, hence forming a sharp (002) peak. The $\gamma$ peak is generally considered to be derived from saturated carbon [50]. To see the changes in the XRD patterns before and after oxidation easily, the peaks in the diffraction range of $2 \theta 10-35^{\circ}$ were fitted to obtain the $\gamma$ and (002) peaks. Figure $4 \mathrm{~b}-\mathrm{d}$ shows $\gamma$ peak and (002) peak for CTP, CTP-10, and CTP-A10, respectively. According to the fitting results in Table $4, \mathrm{~d}_{002}$ of asphalt decreased and $\mathrm{L}_{\mathrm{C}}$ increased after catalytic oxidation, signifying the stacking thickness and ordered arrangement of aromatic planar macromolecules on CTP increased [51]. The $\mathrm{L}_{\mathrm{c}}$ of CTP-A10 increased to $0.026 \mathrm{~nm}$ while CTP-10 did not change, suggesting that the catalysis can promote the intermolecular aromatization reaction. The index $\mathrm{f}_{002}$ of aromaticity decreased, and it is likely that the air oxidation destroyed the aromatic structure of CTP [18], which is consistent with the GC 
detection results. Furthermore, a broad and short bulge appears near $43^{\circ}$, which is thought to be caused by the (100) surface, reflecting the size of aromatic molecules in the CTP [48].

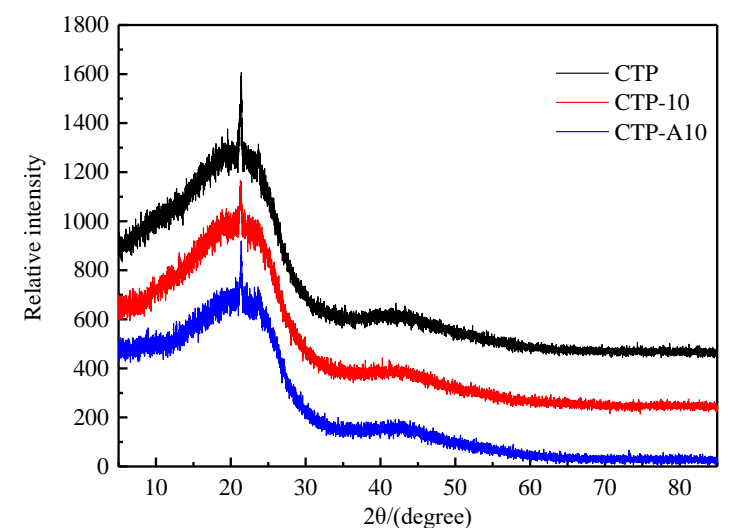

(a)

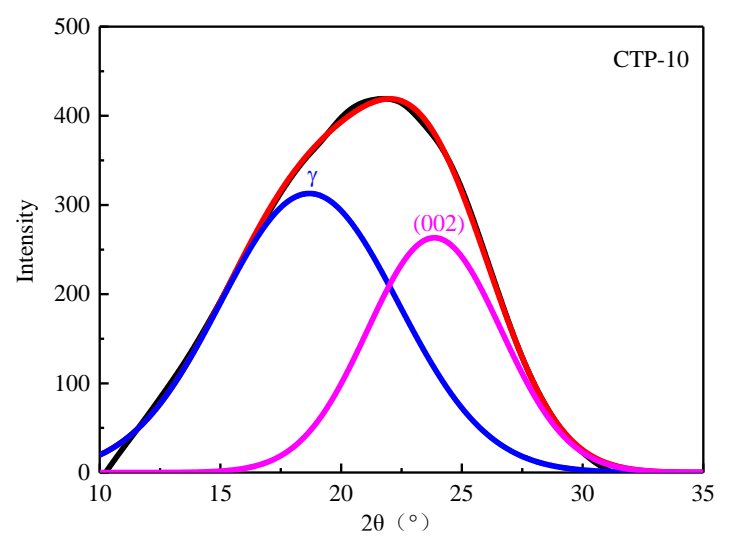

(c)

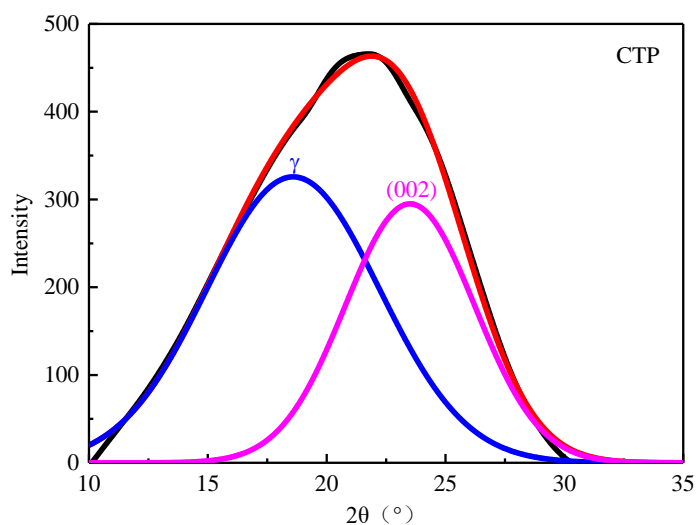

(b)

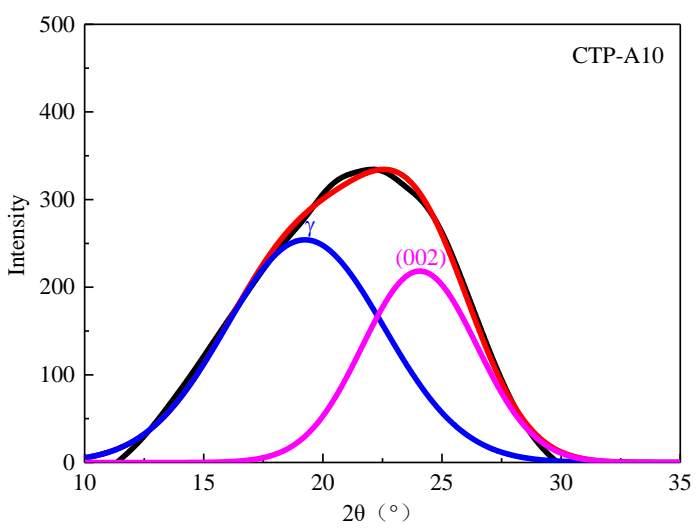

(d)

Figure 4. The X-ray diffraction patterns and peak fitting patterns of the original CTP, the air-oxidized CTP, the catalytic air-oxidized CTP. (a) Original XRD spectra of CTP, CTP-10, and CTP-A10; (b) fitted plot of CTP; (c) fitted plot of CTP-10; (d) fitted plot of CTP-A10.

Table 4. Parameters of XRD spectra.

\begin{tabular}{cccc}
\hline Sample & $\mathbf{d}_{\mathbf{0 0 2}}(\mathbf{n m})$ & $\mathbf{L}_{\mathbf{c}}(\mathbf{n m})$ & $\mathbf{f}_{\mathbf{0 0 2}}$ \\
\hline CTP & 0.3783 & 0.023 & 40.40 \\
CTP-10 & 0.3729 & 0.023 & 38.68 \\
CTP-A10 & 0.3697 & 0.026 & 38.44 \\
\hline
\end{tabular}

Notes: " $\mathrm{d}_{002}$ ", the interlayer spacing; " $\mathrm{L}_{c}$ ", aromatic layer thickness; " $\mathrm{f}_{002}$ ", aromaticity.

\subsubsection{Catalytic Mechanism}

$\mathrm{AlCl}_{3}$ reacts with impurities (e.g., water, halogenates) in the blend to form a complex and further reacts with halogenated as well as unsaturated components to provide initial carbon positive ion. The initial carbon ion attacks the aromatic ring and interacts with $\pi$ electron to give rise to the $\pi$ complex. Then, the aromatic $\sigma$ complex is produced when the carbon ion combines with one of the electrons obtained from the aromatic $\pi$ system. The alkylbenzene is created due to the $\sigma$ complex is unstable and easily dehydrogenated to generate aromatic products, it is easier to alkylate than benzene and can also obtain polyalkyl-substituted aromatic hydrocarbons. As an example, the benzene ring's reaction mechanism catalyzed by $\mathrm{AlCl}_{3}$ is shown in Scheme 3 [52-54]. 


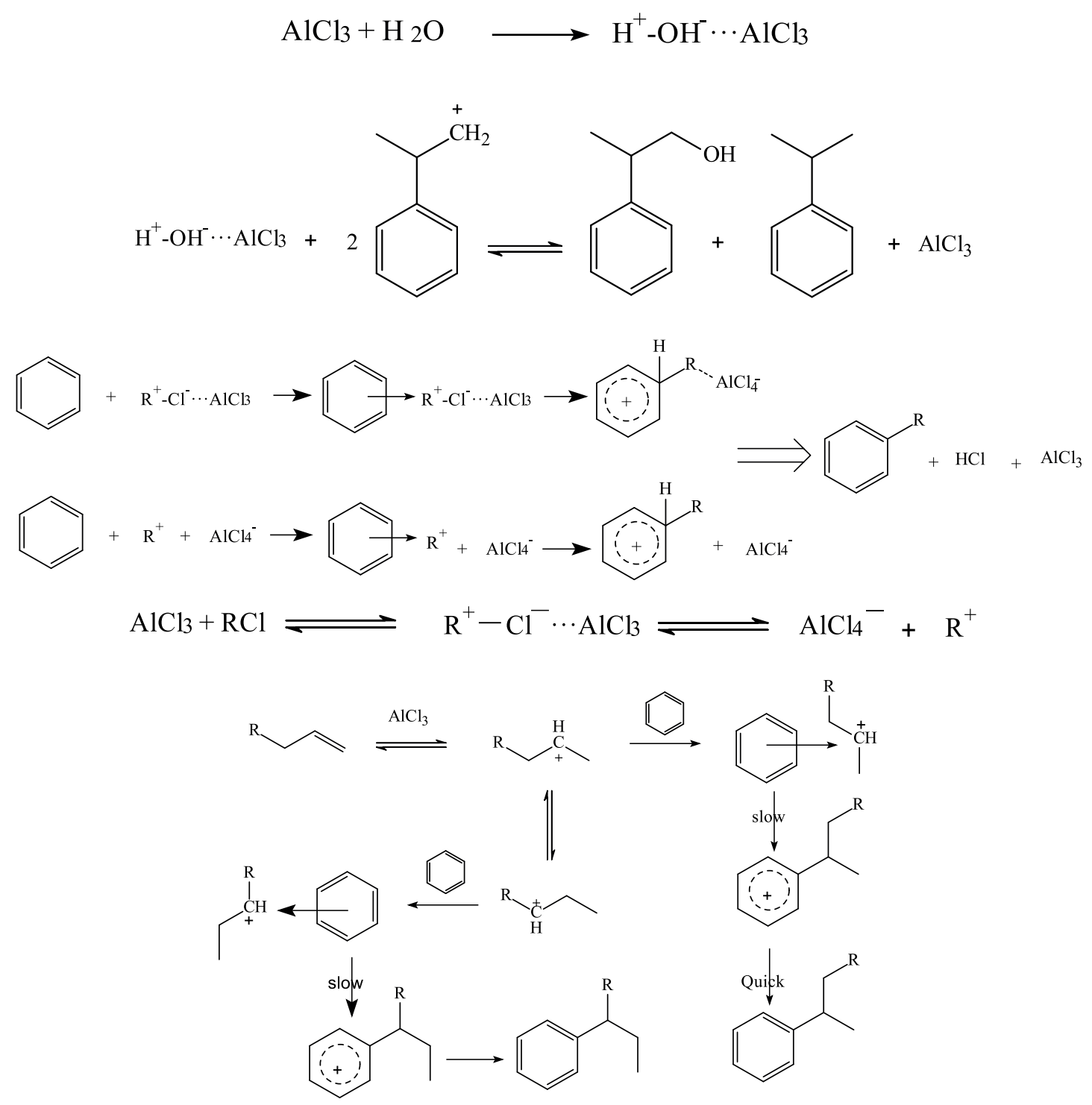

Scheme 3. $\mathrm{AlCl}_{3}$-catalyzed reaction process [52-54].

\subsection{Analysis of PAHs in CTP and Co-Carbonization Processes}

Many coking plants use CTP as a hot binder for coke production since CTP has similar chemical structures with coal and can improve coke quality. There have been many studies on the quality of coke produced by co-coking asphalt with coal, but few on pollutant emissions from co-coking. Therefore, in this study, the effect of air oxidation on the pollutant emissions from co-coking was analyzed to provide guidance for the emission reduction of the coking process.

The PAHs were analyzed by GCMS and the external standard method was used to calculate the content. Mainly, for 16 PAHs proposed by the EPA with carcinogenic, teratogenic, and mutagenic properties. The property of 16 PAHs is listed in Table 5 . The toxicity of each PAH varies and is usually compared using the Benzo(a)pyrene $(\mathrm{BaP})$ toxicity equivalents [55]. Figure 5 shows the GC spectrum of the standard solution at a concentration of $8 \mu \mathrm{g} / \mathrm{mL}$. The peak positions and standard curves of each PAH are shown in Table 6. 
Table 5. Property of 16 PAHs proposed by EPA.

\begin{tabular}{|c|c|c|c|c|c|}
\hline PAHs Species & Chemical Formula & $\begin{array}{l}\text { RPF (Relative } \\
\text { Potency Factor) }\end{array}$ & $\begin{array}{l}\text { Molecular Weight } \\
\text { (g/mol) }\end{array}$ & Abbreviation & Carcinogenic Activity \\
\hline Naphthalene & $\mathrm{C}_{10} \mathrm{H}_{8}$ & 0.000 & 128 & NAP & - \\
\hline Acenaphthylene & $\mathrm{C}_{12} \mathrm{H}_{8}$ & - & 152 & $\mathrm{ACY}$ & - \\
\hline Acenaphthene & $\mathrm{C}_{12} \mathrm{H}_{10}$ & - & 154 & $\mathrm{ACP}$ & - \\
\hline Fluorene & $\mathrm{C}_{13} \mathrm{H}_{8}$ & 0 & 166 & FLR & - \\
\hline Phenanthrene & $\mathrm{C}_{14} \mathrm{H}_{10}$ & 0 & 178 & PHE & - \\
\hline Anthracene & $\mathrm{C}_{14} \mathrm{H}_{10}$ & 0 & 178 & ANT & - \\
\hline Fluoranthene & $\mathrm{C}_{16} \mathrm{H}_{10}$ & 0.034 & 202 & FLT & + \\
\hline Pyrene & $\mathrm{C}_{16} \mathrm{H}_{10}$ & 0.026 & 202 & PYR & - \\
\hline Benzo(a)anthracene & $\mathrm{C}_{18} \mathrm{H}_{12}$ & 0.0 & 228 & $\mathrm{BaA}$ & $-/+$ \\
\hline Chrysene & $\mathrm{C}_{18} \mathrm{H}_{12}$ & 0.033 & 228 & $\mathrm{CHR}$ & + \\
\hline Benzo(k)fluoranthene & $\mathrm{C}_{20} \mathrm{H}_{12}$ & 0.010 & 252 & $\mathrm{BbF}$ & ++ \\
\hline Benzo(b)fluoranthene & $\mathrm{C}_{20} \mathrm{H}_{12}$ & 0.100 & 252 & $\mathrm{BbF}$ & ++ \\
\hline Benzo(a)pyrene & $\mathrm{C}_{20} \mathrm{H}_{12}$ & 1.000 & 252 & $\mathrm{BaP}$ & ++++ \\
\hline Dibenzo(a,h)anthracene & $\mathrm{C}_{22} \mathrm{H}_{14}$ & 1.400 & 278 & DhA & ++ \\
\hline Indeno(1,2,3-ed)pyrene & $\mathrm{C}_{22} \mathrm{H}_{12}$ & 0.100 & 276 & IcP & * \\
\hline Benzo(g,h,i)perylene & $\mathrm{C}_{22} \mathrm{H}_{12}$ & - & 276 & $\mathrm{BgP}$ & ++ \\
\hline
\end{tabular}

Notes: “-", not carcinogenic; "+", carcinogenic/weakly carcinogenic; "++", carcinogenic; "++++", strongly carcinogenic; "*”, carcinogenic has been verified by animal experiments; RPF, BaP equivalent relative carcinogenic coefficient.

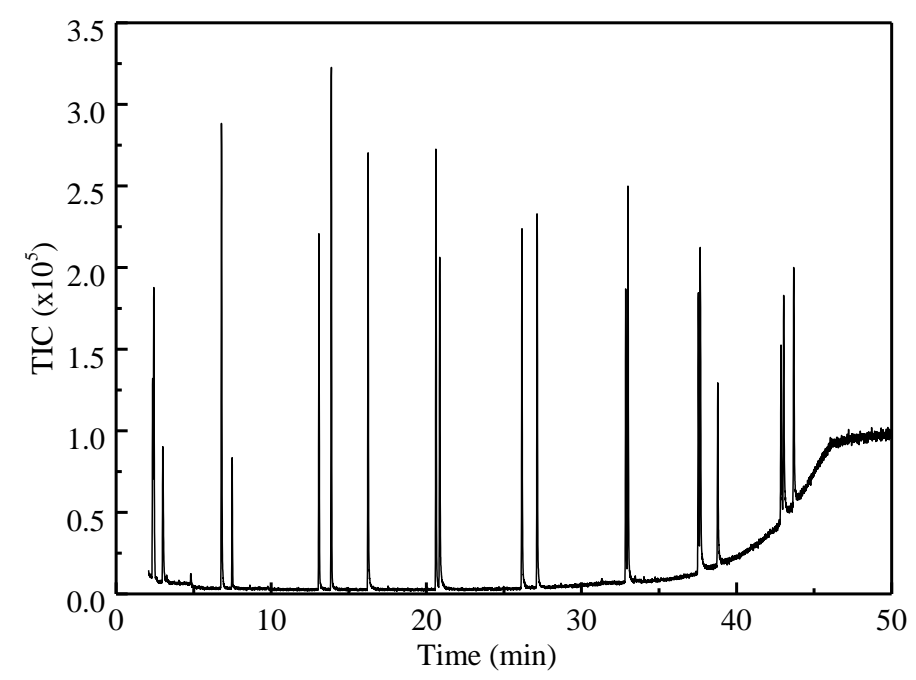

Figure 5. The peak positions of GC spectra of 16 polycyclic aromatic hydrocarbons.

Table 6. Standard curves of 16 PAHs based on the external standard method.

\begin{tabular}{cccc}
\hline PAHs Species & Standard Curves & $\mathbf{R}^{\mathbf{2}}$ & RT \\
\hline NAP & $\mathrm{y}=709.8602 \mathrm{x}^{2}+46,407.3209 \mathrm{x}+4839.9700$ & 0.9998 & 6.794 \\
ACY & $\mathrm{y}=1360.6296 \mathrm{x}^{2}+22,697.9992 \mathrm{x}+1940.4615$ & 0.9999 & 13.078 \\
ACP & $\mathrm{y}=687.4379 \mathrm{x}^{2}+21,084.0115 \mathrm{x}+2137.5146$ & 0.9997 & 13.875 \\
FLR & $\mathrm{y}=869.6043 \mathrm{x}^{2}+21,037.1279 \mathrm{x}+620.3718$ & 0.9999 & 16.243 \\
PHE & $\mathrm{y}=1116.1445 \mathrm{x}^{2}+28,564.8776 \mathrm{x}-4017.3521$ & 0.9999 & 20.620 \\
ANT & $\mathrm{y}=1779.7068 \mathrm{x}^{2}+1824.3099 \mathrm{x}-5537.7252$ & 0.9999 & 20.863 \\
FLT & $\mathrm{y}=1751.0246 \mathrm{x}^{2}+20,353.0331 \mathrm{x}+91.5603$ & 0.9999 & 26.165 \\
PYR & $\mathrm{y}=2114.6845 \mathrm{x}^{2}+18,283.0958 \mathrm{x}+1525.1952$ & 0.9994 & 27.147 \\
BaA & $\mathrm{y}=2005.2859 \mathrm{x}^{2}+7874.1260 \mathrm{x}+1248.1497$ & 0.9998 & 32.853 \\
CHR & $\mathrm{y}=1560.6749 \mathrm{x}^{2}+22,440.6189 \mathrm{x}-6165.9795$ & 0.9998 & 33.003 \\
BbF & $\mathrm{y}=1873.6234 \mathrm{x}^{2}+15,103.7743 \mathrm{x}+1076.7860$ & 0.9999 & 37.658 \\
BbF & $\mathrm{y}=1815.9737 \mathrm{x}^{2}+8108.3877 \mathrm{x}+1751.4327$ & 0.9999 & 37.537 \\
BaP & $\mathrm{y}=1639.6698 \mathrm{x}^{2}+3911.6294 \mathrm{x}+3196.6192$ & 0.9998 & 38.790 \\
DhA & $\mathrm{y}=1340.0057 \mathrm{x}^{2}+5122.8383 \mathrm{x}+2675.9679$ & 0.9992 & 42.867 \\
IcP & $\mathrm{y}=1269.8663 \mathrm{x}^{2}+11,204.3713 \mathrm{x}+2860.1553$ & 0.9997 & 43.693 \\
BgP & $\mathrm{y}=1217.2925 \mathrm{x}^{2}+10,116.6695 \mathrm{x}-98.7201$ & 1.0000 & 43.041 \\
\hline
\end{tabular}


Table 7 shows the 16 PAHs contents in the toluene extract of CTP, and the PAHs content decreased $14.37 \%$ after catalytic oxidation. From Figure 6, the PAHs in the asphalt are mainly five-ring aromatics. Figure 7 shows that the reduction rate of PAHs content decreases as the aromatic hydrocarbon molecules become large. The content of three-ring aromatics was reduced by $67.53 \%$, while the five-ring and six-rings were only reduced by $6.27 \%$ and $5.72 \%$, respectively. This shows that the changes on the larger aromatic molecules are not obvious due to the lower air oxidation temperature and shorter oxidation time. Although small-ring aromatics are reported to have no carcinogenic properties, they have a cancer-promoting effect and are more potentially harmful due to their smaller molecular mass and easier of volatilizing into the air. After air catalytic oxidation, the contents of small-ring aromatics in CTP are significantly reduced, which is essential to reduce the potential harm of CTP.

Table 7. Content and equivalent toxicity of 16 PAHs in pitch and co-carbonated flue gas.

\begin{tabular}{|c|c|c|c|c|c|}
\hline \multirow{2}{*}{ PAHs Species } & \multirow{2}{*}{ Number of Aromatic Rings } & \multicolumn{4}{|c|}{ Sample } \\
\hline & & CTP & CTP-A10 & C-G & C-G-A10 \\
\hline Naphthalene & 2 & - & - & 3.40 & 5.16 \\
\hline Acenaphthylene & \multirow{5}{*}{3} & - & - & 4.9 & 1.28 \\
\hline Acenaphthene & & 0.11 & - & 1.2 & 0.36 \\
\hline Fluorene & & 0.11 & - & 31.0 & 1.92 \\
\hline Phenanthrene & & 0.68 & 0.31 & 233.3 & 8.6 \\
\hline Anthracene & & 0.64 & 0.19 & 82.4 & 2.72 \\
\hline Fluoranthene & \multirow{4}{*}{4} & 1.00 & 0.56 & 129.6 & 18.2 \\
\hline Pyrene & & 1.44 & 0.88 & 94.2 & 15.6 \\
\hline Benzo(a)anthracene & & 2.95 & 2.38 & 78.6 & 15.4 \\
\hline Chrysene & & 1.95 & 1.62 & 72.8 & 15.48 \\
\hline Benzo(k)fluoranthene & \multirow{4}{*}{5} & 1.30 & 1.10 & 22.9 & 4.84 \\
\hline Benzo(b)fluoranthene & & 5.43 & 5.12 & 86.1 & 19.52 \\
\hline Benzo(a)pyrene & & 5.18 & 4.76 & 61.5 & 12.68 \\
\hline Dibenzo(a,h)anthracene & & 3.57 & 3.53 & 17.1 & 2.88 \\
\hline Indeno(1,2,3-ed)pyrene & \multirow{2}{*}{6} & 3.75 & 3.41 & 39.8 & 6.44 \\
\hline Benzo(g,h,i)perylene & & 0.97 & 1.04 & 39.3 & 5.36 \\
\hline \multirow{2}{*}{\multicolumn{2}{|c|}{$\begin{array}{c}\text { Total PAHs (mg/L) } \\
\text { Equivalent Toxic }\end{array}$}} & 29.08 & 24.9 & 998.1 & 136.44 \\
\hline & & 11.24 & 10.66 & 107.52 & 20.89 \\
\hline
\end{tabular}

Notes: "-": not detected; “C-G": PAHs from the flu gas of parent CTP co-carbonated with coal; "C-G-A10": PAHs from the flu gas of CTP catalytic oxidation $10 \mathrm{~h}$ co-carbonated with coal.

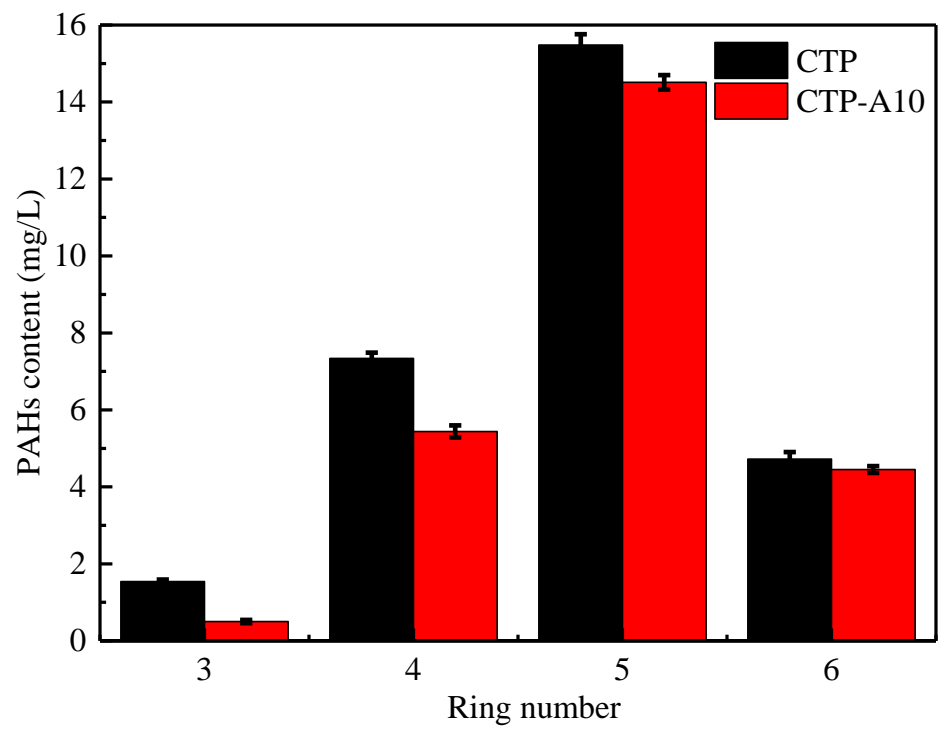

Figure 6. Soluble PAHs content of toluene in raw CTP and the catalytic air-oxidized CTP. Airoxidized CTP. 


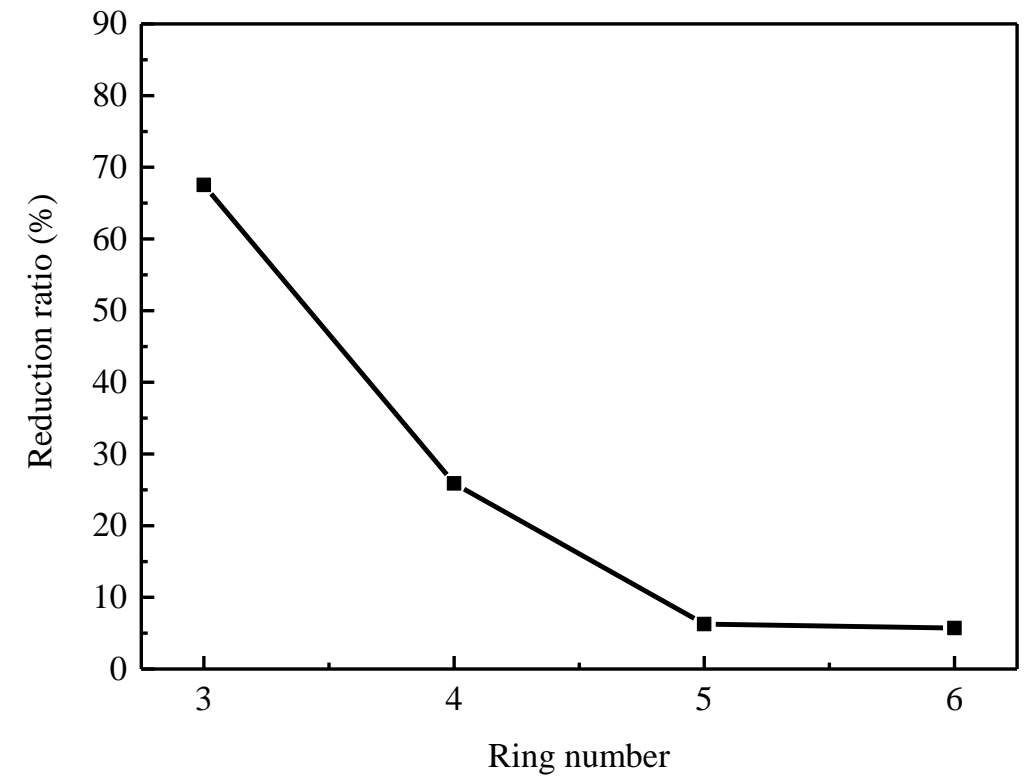

Figure 7. Change rate of PAHs with different ring numbers in CTP after catalytic air oxidation for $10 \mathrm{~h}$.

From Table 7, the proportion of PAHs with a molecular mass between 178 and 278 in CTP is increased after air oxidation, which is beneficial to enhance the coal expansion rate to fill the void between coal particles, thereby increasing the contact between them and reducing the escape of gas during the carbonization process [56]. The PAHs produced by co-carbonization are mainly four-ring aromatic hydrocarbons, shown in Figure 8 [34,35]. The use of air catalytic oxidation CTP significantly reduces the emission of PAHs during the co-carbonization process, which is of great meaningful results for environmental pollution prevention and control of the coking industry.

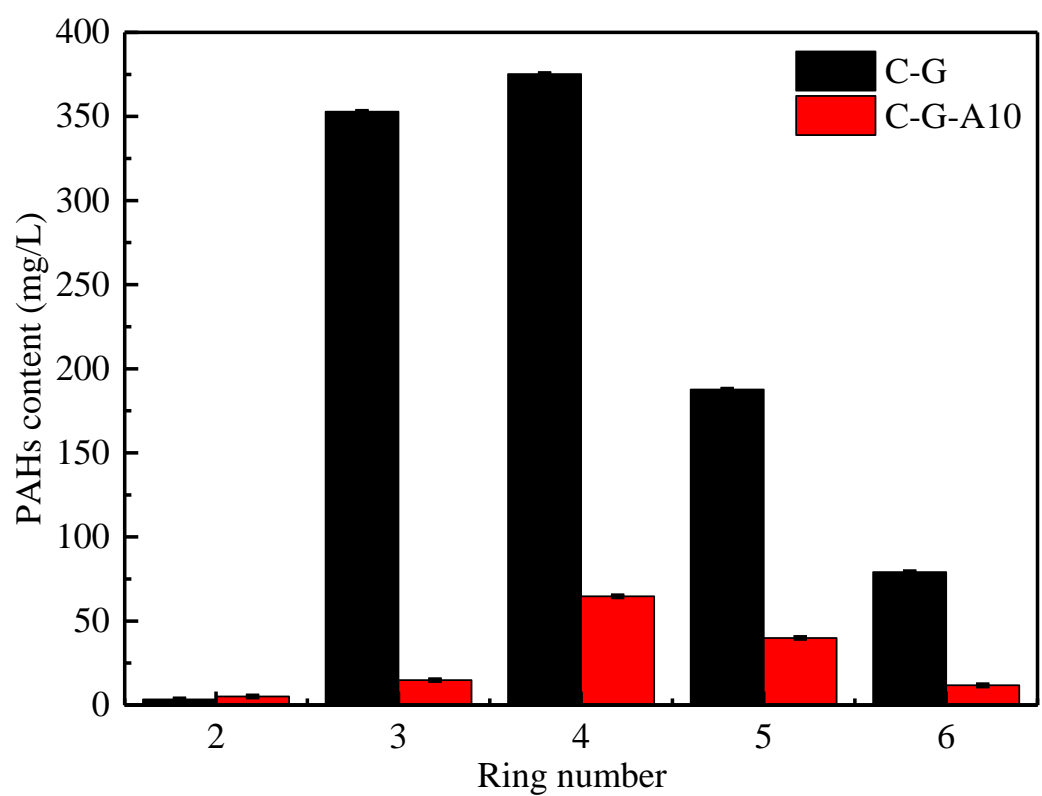

Figure 8. Content of different ring number PAHs in flue gas of coal and pitch co-carbonization (C-G: PAHs in flue gas co-carbonized by coal and original CTP; C-G-A10: PAHs in flue gas cocarbonized by coal and the catalytic air-oxidized CTP). 


\section{Materials and Experiments}

\subsection{Raw Materials}

The CTP used in the experiments was purchased from a domestic asphalt sales company. Table 8 lists the characteristics of coal samples from a coking plant in Shanxi, China. The catalyst used was $\mathrm{AlCl}_{3}$ with analytically pure.

Table 8. Industrial analysis of four materials.

\begin{tabular}{|c|c|c|c|c|}
\hline Sample & $M_{a d}(\%)$ & $A_{a d}(\%)$ & $\mathrm{V}_{\mathrm{ad}}(\%)$ & $\mathrm{FC}_{\mathrm{ad}}(\%)$ \\
\hline JF & 19.76 & 10.69 & 3.48 & 66.07 \\
\hline$X Y$ & 8.39 & 7.54 & 14.72 & 69.35 \\
\hline XS & 1.12 & 6.23 & 15.42 & 77.23 \\
\hline XJ & 4.88 & 7.43 & 14.46 & 73.23 \\
\hline
\end{tabular}

\subsection{Preparation of Air-Oxidation Modified Coal Tar Pitch}

The raw material was mixed with $1.5 \% \mathrm{AlCl}_{3}$ and put into a corundum boat. Then the corundum boat with the samples was put into a tube furnace preheated to $200{ }^{\circ} \mathrm{C}$ for catalytic oxidation. The tube furnace size is $60 \mathrm{~mm} \times 1000 \mathrm{~mm}$. For convenience, the CTP oxidized for $0 \mathrm{~h}, 1 \mathrm{~h}, 3 \mathrm{~h}, 6 \mathrm{~h}$, and $10 \mathrm{~h}$ are expressed as CTP, CTP-1, CTP-3, CTP-6, and CTP-10 respectively. The coal tar pitch oxidized for $1 \mathrm{~h}, 3 \mathrm{~h}, 6 \mathrm{~h}$, and $10 \mathrm{~h}$ after adding catalyst is expressed as CTP-A1, CTP-A3, CTP-A6, and CTP-A10, respectively.

\subsection{Analytical Testing}

Samples were prepared according to the method described in GB/T 2291-2016 [57]. V, TI, and CV are measured according to GB/T 2001-2013 [58], GB/T 2292-2018 [59], and GB/T 8727-2008 [60], respectively. C, H, O, N, and S were analyzed by Elementar Vario Cube (Langenselbold, Germany). FTIR spectroscopic analyses were performed using NICOLET iS10 of ThermoFisher Scientific, Waltham, MA, USA. The KBr tablet method was used, and the ratio of KBr to sample was 100:1. The XRD test used D8 ADVANCE from Bruker axs, Karlsruhe, Germany. Experimental conditions: step size is $0.01^{\circ}$, scanning speed is $8^{\circ} / \mathrm{min}$, scanning range is $5-85^{\circ}, \mathrm{Cu}$ target, $\mathrm{K} \alpha$ radiation.

\subsection{Polycyclic Aromatic Hydrocarbon Detection \\ 3.4.1. Gas Chromatography Analysis}

GC analyses were performed on an Agilent chromatography, using a DB-5 column. The carrier gas is high-purity nitrogen with a flow rate of $4 \mathrm{~mL} / \mathrm{min}$. Heating program: $5{ }^{\circ} \mathrm{C} / \mathrm{min}$, from $100{ }^{\circ} \mathrm{C}$ to $300{ }^{\circ} \mathrm{C}$, constant temperature time is $10 \mathrm{~min}$. The injection port temperature is $300{ }^{\circ} \mathrm{C}$, the injection volume is $1 \mu \mathrm{L}$, the split ratio is $10: 1$, and the FID detector is used. The external standard curve method was used to analyze the content of PAHs. The concentration gradient of the standard solution used were $0.8,1.6,3.2,4.0$, and $8.0 \mu \mathrm{g} / \mathrm{mL}$.

\subsubsection{Collection of PAHs from CTP}

Firstly, the quartz sand and filter paper cartridges were soaked in toluene for more than $24 \mathrm{~h}$ and dried to constant weight at $115^{\circ} \mathrm{C}$. Next, $1 \mathrm{~g}$ of the sieved sample $(<0.125 \mathrm{~mm})$ was placed in a filter paper cartridge pre-placed with $10 \mathrm{~g}$ of quartz sand $(3-6 \mathrm{~mm})$, mixed them thoroughly and placed in a Soxhlet extractor before adding $30 \mathrm{~mL}$ of toluene. An additional $120 \mathrm{~mL}$ of toluene was added to the round-bottom flask. Then, the Soxhlet extraction device was assembled and the heater was adjusted to make the solvent reflux for one time within $90 \mathrm{~s}$. The solvent in the siphon tube was clear and colorless after $8 \mathrm{~h}$ of continues extraction. Finally, a rotary evaporator was used to treat the extraction solvent, and the residue was diluted to $50 \mathrm{~mL}$ with dichloromethane. 


\subsubsection{Collection of PAHs in Pyrolysis Gas from CTP and Coal Co-Carbonization}

The mixed samples (96 wt. \% coal $+4 \mathrm{wt} . \%$ CTP/CTP-A10) were loaded into a $50 \mathrm{~mL}$ corundum boat and pressed to a bulk density of $0.9 \mathrm{t} / \mathrm{m}^{3}$. Then, it was carbonized in an $\mathrm{N}_{2}$ atmosphere using a tube furnace equipped with a glass fiber filter membrane. After collection, the filter membrane was chopped and placed in a centrifuge tube with $10 \mathrm{~mL}$ of dichloromethane, followed by sonication and centrifugation for $30 \mathrm{~min}$, respectively. The supernatant after centrifugation was filtered through a $0.22 \mu \mathrm{m}$ needle filter and analyzed by gas chromatography.

\section{Conclusions}

In this study, the air oxidation of CTP can be divided into two processes: (1) volatilization of light components, and (2) molecular condensation reaction. The increase in the atomic $\mathrm{C} / \mathrm{H}$ ratio and oxygen content of CTP occurs during its air oxidation process. $\mathrm{AlCl}_{3}$ catalysis accelerates the introduction of oxygen in CTP significantly, while different degrees of dehydrogenation reactions are taken place. In the CTP air oxidation process, the content of oxygen-containing functional groups - $\mathrm{OH}$ and $\mathrm{C}-\mathrm{O}-\mathrm{C}$ are increased, and an arylcycloalkylation reaction has been observed. Besides, the content of toluene-soluble toxic PAHs in CTP is reduced due to the deepened molecules condensation and the decreased aromaticity. The emissions of toxic PAHs during co-carbonization with coal are diminished significantly due to the CTP catalytic oxidation, which is of great significance for environmental pollution prevention and control of the coking industry.

Author Contributions: Data curation, J.W. and Y.Z.; Formal analysis, J.W. and Y.Z.; Investigation, L.C., J.W. and Y.Z.; Project administration, J.W.; Resources, P.L. and Y.Z.; Writing original draft, L.C.; Writing review \& editing, L.C., F.G. and J.W. All authors have read and agreed to the published version of the manuscript.

Funding: This work was funded by the Natural Science Foundation of Shandong Province (ZR2020KE044), the National Natural Science Foundation of China (51974311), the National Key R\&D Program of China (2019YFC1904302), the Foundation of State Key Laboratory of High-efficiency Utilization of Coal and Green Chemical Engineering (2019-KF-02) and the Yulin University and the Dalian National Laboratory for Clean Energy (YLU-DNL Fund 2021005).

Data Availability Statement: Data is contained within the article.

Conflicts of Interest: The authors declare no conflict of interest.

\section{References}

1. Hung, A.M.; Fini, E.H. Absorption spectroscopy to determine the extent and mechanisms of aging in bitumen and asphaltenes. Fuel 2019, 242, 408-415. [CrossRef]

2. Chen, J.S.; Huang, L.S. Developing an aging model to evaluate engineering properties of asphalt paving binders. Mater. Struct. 2000, 33, 559-565. [CrossRef]

3. Marsac, P.; Piérard, N.; Porot, L.; Van den Bergh, W.; Grenfell, J.; Mouillet, V.; Pouget, S.; Besamusca, J.; Farcas, F.; Gabet, T.; et al. Potential and limits of FTIR methods for reclaimed asphalt characterisation. Mater. Struct. 2014, 47, 1273-1286. [CrossRef]

4. Yang, Z.; Zhang, X.; Zhang, Z.; Zou, B.; Zhu, Z.; Lu, G.; Xu, W.; Yu, J.; Yu, H. Effect of Aging on Chemical and Rheological Properties of Bitumen. Polymers 2018, 10, 1345. [CrossRef] [PubMed]

5. Petrova, B.; Budinova, T.; Petrov, N.; Yardim, M.F.; Ekinci, E.; Razvigorova, M. Effect of different oxidation treatments on the chemical structure and properties of commercial coal tar pitch. Carbon 2005, 43, 261-267. [CrossRef]

6. Quddus, M.A.; Sarwar, S.N.; Khan, F. The chemical composition of catalytic air blown asphalt. Fuel 1995, 74, 684-689. [CrossRef]

7. Oldham, D.J.; Obando, C.J.; Mousavi, M.; Kaloush, K.E.; Fini, E.H. Introducing the critical aging point (CAP) of asphalt based on its restoration capacity. Constr. Build. Mater. 2021, 278, 122379. [CrossRef]

8. Mousavi, M.; Pahlavan, F.; Oldham, D.; Hosseinnezhad, S.; Fini, E.H. Multiscale Investigation of Oxidative Aging in Biomodified Asphalt Binder. J. Phys. Chem. C 2016, 120, 17224-17233. [CrossRef]

9. Benk, A. Utilisation of the binders prepared from coal tar pitch and phenolic resins for the production metallurgical quality briquettes from coke breeze and the study of their high temperature carbonization behaviour. Fuel Process. Technol. 2010, 91, 1152-1161. [CrossRef]

10. Xu, G.Y.; Yan, Q.; Yu, H.F.; Zhang, J.; An, B.G.; Wang, T.J.; Qu, D.L.; Zhou, W.M. Tracking and analyzing the structures and morphologies of mesocarbon microbeads (MCMBs) in air oxidation process. Polym. Bull. 2016, 73, 3175-3182. [CrossRef] 
11. Yu, B.; Wang, C.; Chen, M.; Zheng, J.; Qi, J. Two-step chemical conversion of coal tar pitch to isotropic spinnable pitch. Fuel Process. Technol. 2012, 104, 155-159. [CrossRef]

12. Sun, M.; Wang, L.; Zhong, J.; Yao, Q.; Chen, H.; Jiao, L.; Hao, Q.; Ma, X. Chemical modification with aldehydes on the reduction of toxic PAHs derived from low temperature coal tar pitch. J. Anal. Appl. Pyrolysis 2020, 148, 104822. [CrossRef]

13. Russo, C.; Ciajolo, A.; Stanzione, F.; Tregrossi, A.; Oliano, M.M.; Carpentieri, A.; Apicella, B. Investigation on chemical and structural properties of coal- and petroleum-derived pitches and implications on physico-chemical properties (solubility, softening and coking). Fuel 2019, 245, 478-487. [CrossRef]

14. Zhang, S.; Cui, Y.; Wei, W. Low-temperature characteristics and microstructure of asphalt under complex aging conditions. Constr. Build. Mater. 2021, 303, 124408. [CrossRef]

15. Li, X.; Wang, Y.-M.; Wu, Y.-L.; Wang, H.-R.; Chen, M.; Sun, H.-D.; Fan, L. Properties and modification mechanism of asphalt with graphene as modifier. Constr. Build. Mater. 2020, 272, 121919. [CrossRef]

16. Nie, Y.; Gao, W.; Zhou, C.; Yu, P.; Song, X. Evaluation of ageing behaviors of asphalt binders using FTIR tests. Int. J. Pavement Res. Technol. 2020, 14, 615-624. [CrossRef]

17. Li, K.; Liu, Q.; Cheng, H.; Hu, M.; Zhang, S. Classification and carbon structural transformation from anthracite to natural coaly graphite by XRD, Raman spectroscopy, and HRTEM. Spectrochim. Acta Part A Mol. Biomol. Spectrosc. 2021, $249,119286$. [CrossRef] [PubMed]

18. Siddiqui, M.N.; Ali, M.F.; Shirokoff, J. Use of X-ray diffraction in assessing the aging pattern of asphalt fractions. Fuel 2002, 81, 51-58. [CrossRef]

19. Yaro, N.S.A.; Bin Napiah, M.; Sutanto, M.H.; Usman, A.; Saeed, S.M. Modeling and optimization of mixing parameters using response surface methodology and characterization of palm oil clinker fine modified bitumen. Constr. Build. Mater. 2021, 298, 123849. [CrossRef]

20. Kargar-Shouroki, F.; Miri, M.; Sakhvidi, M.J.Z.; Sangchi, S.Z.H.; Madadizadeh, F. Genotoxic effect of exposure to polycyclic aromatic hydrocarbons (PAHs) in asphalt workers. EXCLI J. 2021, 20, 686-697. [CrossRef] [PubMed]

21. Bal, C.; Ağış, E.R.; Büyükşekerci, M.; Gunduzoz, M.; Tutkun, L.; Yılmaz, H. Occupational exposure to asphalt fume can cause oxidative DNA damage among road paving workers. Am. J. Ind. Med. 2018, 61, 471-476. [CrossRef]

22. Liu, X.; Zhao, D.; Peng, L.; Bai, H.; Zhang, D.; Mu, L. Gas-particle partition and spatial characteristics of polycyclic aromatic hydrocarbons in ambient air of a prototype coking plant. Atmos. Environ. 2019, 204, 32-42. [CrossRef]

23. Lin, S.; Hung, W.; Leng, Z. Air pollutant emissions and acoustic performance of hot mix asphalts. Constr. Build. Mater. 2016, 129, 1-10. [CrossRef]

24. Wang, Y.-G.; Jiang, W.-J.; Shen, J.; Wang, W.; Niu, Y.-X.; Zhao, W.; Wei, X.-Y. Detoxification modification of coal-tar pitch by ultraviolet \& microwave radiation-enhanced chemical reaction and toxicity evaluation by chemical index and cytotoxicity assay in vitro. J. Hazard. Mater. 2021, 410, 124648. [CrossRef] [PubMed]

25. Lei, M.; Wu, S.; Liu, G.; Amirkhanian, S. VOCs characteristics and their relation with rheological properties of base and modified bitumens at different temperatures. Constr. Build. Mater. 2018, 160, 794-801. [CrossRef]

26. Law, B.F.; Stone, S.; Frazer, D.; Siegel, P.D. Characterization of Laboratory Simulated Road Paving-Like Asphalt by HighPerformance Liquid Chromatography and Gas Chromatography-Mass Spectrometry. J. Occup. Environ. Hyg. 2006, 3, 343-350. [CrossRef] [PubMed]

27. Buratti, M.; Campo, L.; Fustinoni, S.; Valla, C.; Martinotti, I.; Cirla, P.E.; Cavallo, D.; Foà, V. Application of Ultraviolet Spectrophotometry to Estimate Occupational Exposure to Airborne Polyaromatic Compounds in Asphalt Pavers. J. Occup. Environ. Hyg. 2007, 4, 412-419. [CrossRef]

28. Nomura, S.; Arima, T. Influence of binder (coal tar and pitch) addition on coal caking property and coke strength. Fuel Process. Technol. 2017, 159, 369-375. [CrossRef]

29. Zubkova, V.; Prezhdo, V. The formation of mesophase composites under influence of the coal-tar pitch during coal carbonization. Compos. Interfaces 2005, 12, 523-544. [CrossRef]

30. Ehrburger, P.; Lahaye, J. Physico-chemical interactions of coal and pitch during co-carbonization. Fuel 1984, 63, 494-498. [CrossRef]

31. Xu, R.; Deng, S.; Wang, W.; Zheng, H.; Chen, S.; Huang, X.; Wang, F. Effect of Binders on the Crushing Strength of Ferro-Coke. Materials 2021, 14, 850. [CrossRef] [PubMed]

32. Zhang, Q.; Meng, J.; Su, G.; Liu, Z.; Shi, B.; Wang, T. Source apportionment and risk assessment for polycyclic aromatic hydrocarbons in soils at a typical coking plant. Ecotoxicol. Environ. Saf. 2021, 222, 112509. [CrossRef]

33. Xiong, G.; Zhang, Y.; Duan, Y.; Cai, C.; Wang, X.; Li, J.; Tao, S.; Liu, W. Uptake of PAHs by cabbage root and leaf in vegetable plots near a large coking manufacturer and associations with PAHs in cabbage core. Environ. Sci. Pollut. Res. 2017, $24,18953-18965$. [CrossRef] [PubMed]

34. Shi, Y.; Song, C.Y.; Gao, L. Generation Characteristics of Polycyclic Aromatic Hydrocarbons during Blending Coal Coking. Adv. Mater. Res. 2011, 418-420, 424-427. [CrossRef]

35. Shi, Y.; Yue, Z.X. Generation and Emission Characteristics of Polycyclic Aromatic Hydrocarbons in Single Coal Coking Process. Adv. Mater. Res. 2011, 402, 442-445. [CrossRef]

36. Cheng, X.-L.; Li, E.-K.; Cang, D.-Q.; Shi, Y.; Li, M.-J. Generation of polycyclic aromatic hydrocarbons during coking. J. Iron Steel Res. Int. 2010, 17, 6-10. [CrossRef] 
37. Duan, M.; Tian, Y.-M.; Li, S.-Z. The catalytic role of aluminium trichloride in the polymerization and carbonization of coal tar. New Carbon Mater. 2016, 31, 62-67. [CrossRef]

38. Qizhi, P. Organic chemical reactions catalyzed by $\mathrm{AlCl}_{3}$. Chem. Enterp. Manag. 2014, 20, 73-75. (In Chinese)

39. Cao, B.; Du, J.; Cao, Z.; Sun, H.; Sun, X.; Fu, H. Theoretical study on the alkylation of o-xylene with styrene in $\mathrm{AlCl}_{3}$-ionic liquid catalytic system. J. Mol. Graph. Model. 2017, 74, 8-15. [CrossRef]

40. Vermeeren, P.; Hamlin, T.A.; Fernández, I.; Bickelhaupt, F.M. How Lewis Acids Catalyze Diels-Alder Reactions. Angew. Chem. Int. Ed. 2020, 59, 6201-6206. [CrossRef]

41. Fernández, J.; Figueiras, A.; Granda, M.; Bermejo, J.; Menéndez, R. Modification of coal-tar pitch by air-blowing-I. Variation of pitch composition and properties. Carbon 1995, 33, 295-307. [CrossRef]

42. Barr, J.B.; Lewis, I.C. Chemical changes during the mild air oxidation of pitch. Carbon 1978, 16, 439-444. [CrossRef]

43. Xiong, J.M.; Ma, W.M.; Ge, M.L.; Li, W.H.; Chen, X. Preparation of high quality impregnating pitch by new route. Mater. Res. Innov. 2014, 18, S2-924-S2-927. [CrossRef]

44. Ashworth, C. Asphalt a concern for air pollution. Nat. Rev. Earth Environ. 2020, 1, 497. [CrossRef]

45. Ozaki, A.; Taylor, H.S.; Boudart, B. Kinetics and mechanism of the ammonia synthesis. Proc. R. Soc. Lond. Ser. A Math. Phys. Sci. 1960, 258, 47-62. [CrossRef]

46. Hao, J.; Feng, W.; Qiao, Y.; Tian, Y.; Zhang, J.; Che, Y. Thermal cracking behaviors and products distribution of oil sand bitumen by TG-FTIR and Py-GC/TOF-MS. Energy Convers. Manag. 2017, 151, 227-239. [CrossRef]

47. Liu, H.; Li, T.; Wang, X.; Zhang, W.; Zhao, T. Preparation and characterization of carbon foams with high mechanical strength using modified coal tar pitches. J. Anal. Appl. Pyrolysis 2014, 110, 442-447. [CrossRef]

48. Niu, Z.-S.; Wang, Y.-G.; Shen, J.; Niu, Y.-X.; Liu, G.; Zhao, W.; Wei, X.-Y. Insight into aromatic structures of a middle-temperature coal tar pitch by direct characterization and ruthenium ion-catalyzed oxidation. Fuel 2019, 241, 1164-1171. [CrossRef]

49. Khordehbinan, M.; Kaymanesh, M.R. Chemical analysis and middle-low temperature functional of waste polybutadiene rubber polymer modified bitumen. Pet. Sci. Technol. 2019, 38, 8-17. [CrossRef]

50. Tong, J.; Han, X.; Wang, S.; Jiang, X. Evaluation of Structural Characteristics of Huadian Oil Shale Kerogen Using Direct Techniques (Solid-State 13C NMR, XPS, FT-IR, and XRD). Energy Fuels 2011, 25, 4006-4013. [CrossRef]

51. Zhang, X.; Ma, Z.; Meng, Y.; Xiao, M.; Fan, B.; Song, H.; Yin, Y. Effects of the addition of conductive graphene on the preparation of mesophase from refined coal tar pitch. J. Anal. Appl. Pyrolysis 2019, 140, 274-280. [CrossRef]

52. Duan, H.; Xu, X.; Leng, K.; Guo, G.; Yu, Q.; Li, X.; Han, Y.; Gao, J.; Wang, Z. $\mathrm{AlCl}_{3}$-catalyzed C-H p hosphination of benzene: A mechanistic study. Appl. Catal. A Gen. 2020, 611, 117943. [CrossRef]

53. Zhengping, G.Z.F. In situ capacitance enhancement and catalytic degradation of Friedel-Crafts alkylation reaction in polymer blends. J. High. Educ. Chem. 2009, 30, 1898-1903. (In Chinese)

54. Li, Y.; Peng, D.; Guan, C. Advances in catalytic mechanisms for the alkylation of aromatics and olefins. Adv. Chem. Eng. 2020, 39, 204-211. (In Chinese) [CrossRef]

55. Wang, W.; Liu, G.; Shen, J.; Chang, H.; Li, R.; Du, J.; Yang, Z.; Xu, Q. Reducing polycyclic aromatic hydrocarbons content in coal tar pitch by potassium permanganate oxidation and solvent extraction. J. Environ. Chem. Eng. 2015, 3, 1513-1521. [CrossRef]

56. Hayashizaki, H.; Kanehashi, K.; Uebo, K.; Nomura, S.; Saito, Y.; Matsushita, Y.; Aoki, H. Effects of Hydrocarbon Addition on Increase in Dilatation of Coal. ISIJ Int. 2019, 59, 1404-1412. [CrossRef]

57. Standardization Administration of China. GB/T 2291-2016. Method for Preparation of Coal Tar Pitch Specimens. Available online: http:/ / openstd.samr.gov.cn/bzgk/gb/newGbInfo?hcno=625BFF4DB191ADBB18D5511A13D5AA99 (accessed on 13 December 2016). (In Chinese)

58. Standardization Administration of China. GB/T 2001-2013. Coke-Determination of Proximate Analysis. Available online: http:/ / openstd.samr.gov.cn/bzgk/gb/newGbInfo?hcno=CB44EEDFCC1A86A2B82304382DD94760 (accessed on 17 December 2013). (In Chinese)

59. Standardization Administration of China. GB/T 2292-2018. Determination of Toluene Insoluble Content for Coking Products. Available online: http:/ / openstd.samr.gov.cn/bzgk/gb/newGbInfo?hcno=EA5BFD7C1E8CD5C70F1F02EF7AB754D8 (accessed on 14 May 2018). (In Chinese)

60. Standardization Administration of China. GB/T 8727-2008. Method for Determination of Coking Value of Coal Pitch Products. Available online: http:/ / openstd.samr.gov.cn/bzgk/gb/newGbInfo?hcno=707FCEA906B79320A1CB1878F347AE91 (accessed on 19 August 2008). (In Chinese) 